$$
\begin{aligned}
& \text { ANL/MSD/CP- } 89509 \\
& \text { CONF- } 9508 / 63--3
\end{aligned}
$$

TELE-PRESENCE MICROSCOPY: AN INTERACTIVE MULTI-USER ENVIRONMENT FOR COLLABORATIVE RESEARCH USING HIGH SPEED NETWORKS AND THE INTERNET*

\author{
N.J. Zaluzec, \\ Center for Electron Microscopy, \\ 9700 S. Cass Ave. Bldg. 212 \\ Argonne National Laboratory, Argonne, IL 60439 \\ JUL 18 19\%0
}

RECEIVED

March 1996

The submitted manuscript has been authored by a
contractor of the U.S. Covernment under contract
No. W-3t-109-ENG-38. Accordingly, the U.S.
Government retains a nonexclusive, royalty-free
license to publish or reproduce the published form
of this contribution, or allow others to do so, for
U.S. Government purposes.

Published in Proceedings of the Microscopy Society of America Annual Meeting, Kansas City, MO, August 13-17, 1995. Published in Proc. Microscopy and Microanalysis.

*Work supported in part by the U. S. Department of Energy, BES-Materials Sciences, under Contract W-31-109-ENG-38. 


\section{DISCLAIMER}

This report was prepared as an account of work sponsored by an agency of the United States Government. Neither the United States Government nor any agency thereof, nor any of their employees, makes any warranty, express or implied, or assumes any legal liability or responsibility for the accuracy, completeness, or usefulness of any information, apparatus, product, or process disclosed, or represents that its use would not infringe privately owned rights. Reference herein to any specific commercial product, process, or service by trade name, trademark, manufacturer, or otherwise does not necessarily constitute or imply its endorsement, recommendation, or favoring by the United States Government or any agency thereof. The views and opinions of authors expressed herein do not necessarily state or reflect those of the United States Government or any agency thereof. 


\title{
Tele-Presence Microscopy: An Interactive Multi-User Environment For Collaborative Research using High Speed Networks and The Internet
}

\author{
Nestor J. Zaluzec \\ Materials Science Division, Kinetics \& Irradiation Effects Group \\ Argonne National Laboratory, Argonne, Illinois 60439 , USA
}

Tele-Presence Microscopy (TPM) is an advanced concept in the integration of computers and high speed networks with scientific instruments for operation, control, communication and research which makes use of ANL's Advanced Analytical Electron Microscope (AAEM) and Analytical Scanning Electron Microscope (ASEM) as development/testbed sites ${ }^{1}$. The implementation of a Tele-Presence Microscopy Facility allows a user from a remote location to either observe and/or control state-of-the-art instrumentation in a real time interactive mode. Using TPM, a user will be able to actively participate in scientific investigations at unique resources such as user facilities without being physically present at those locations. Manufacturers would be able to configure demonstration equipment which are accessible via the TPM system and thus allow prospective customers to remotely evaluate instrumentation before purchase. After acquisition, implementation by the manufacturer of a TPM system would allow remote service/diagnostics by a systems engineer who resides at the manufacturing site. Finally in an educational environment, students can initiate tele-presence operation of instruments which may not be available at their host institution, allowing widest possible access to unique facilities, Alternatively, should students have access to local equipment, they will have the opportunity of consulting an advisor or non-local expert in the field in an on-line mode during their actual experimental session, thus freeing valuable time which would be otherwise wasted during unproductive experiments. Several remote operation concepts have been suggested and partially implemented ${ }^{2-4}, T P M$ when linked with the LabSpace ${ }^{1}$ represents a superset of these ideas, in that it is applicable to not only all microscopies but all scientific instrumentation in general.

The generic TPM/LabSpace system is composed of both software and hardware, which operate in a client/server relationship (figure 1). The local operator would be able to control access to the instrument, via a secure login system granting either observation mode or control mode to a remote access request. The remote TPM user would be present at a workstation displaying system configured windows showing relevant experimental details ( microscope room \& inhabitants, images, spectra, instrument \&/or control parameters. see figure 2.), which would be either active or passive, depending upon the granted operational mode. Hot links would be provided so that it will be possible to integrate special resources (such as massively parallel computers) needed for data processing and analysis, when they are available either locally or remotely. The TPM workstation client software is being designed to be as platform independent as possible (i.e. capable of running on most high end workstations Mac's, PC's, Sun's....) and will therefore allow the user community widest access at minimum cost. The TPM/LabSpace proposal is a multi-year program to develop a permanent Tele-Presence Facility providing a continuous presence on the Internet for the microscopy community. Generic TPM client software for this instrumentation will be distributed free of charge to all interested organizations. The current status of the TPM project can be checked by accessing the Microscopy and Microanalysis WWW Site (URL= $h t t p: / / w w w . a m c . a n l . g o v)$. This site provides a demonstration of some of the capabilities of a passive link using conventional WWW browsing tools . 


\section{TPM/LabSpace Architecture Overview}
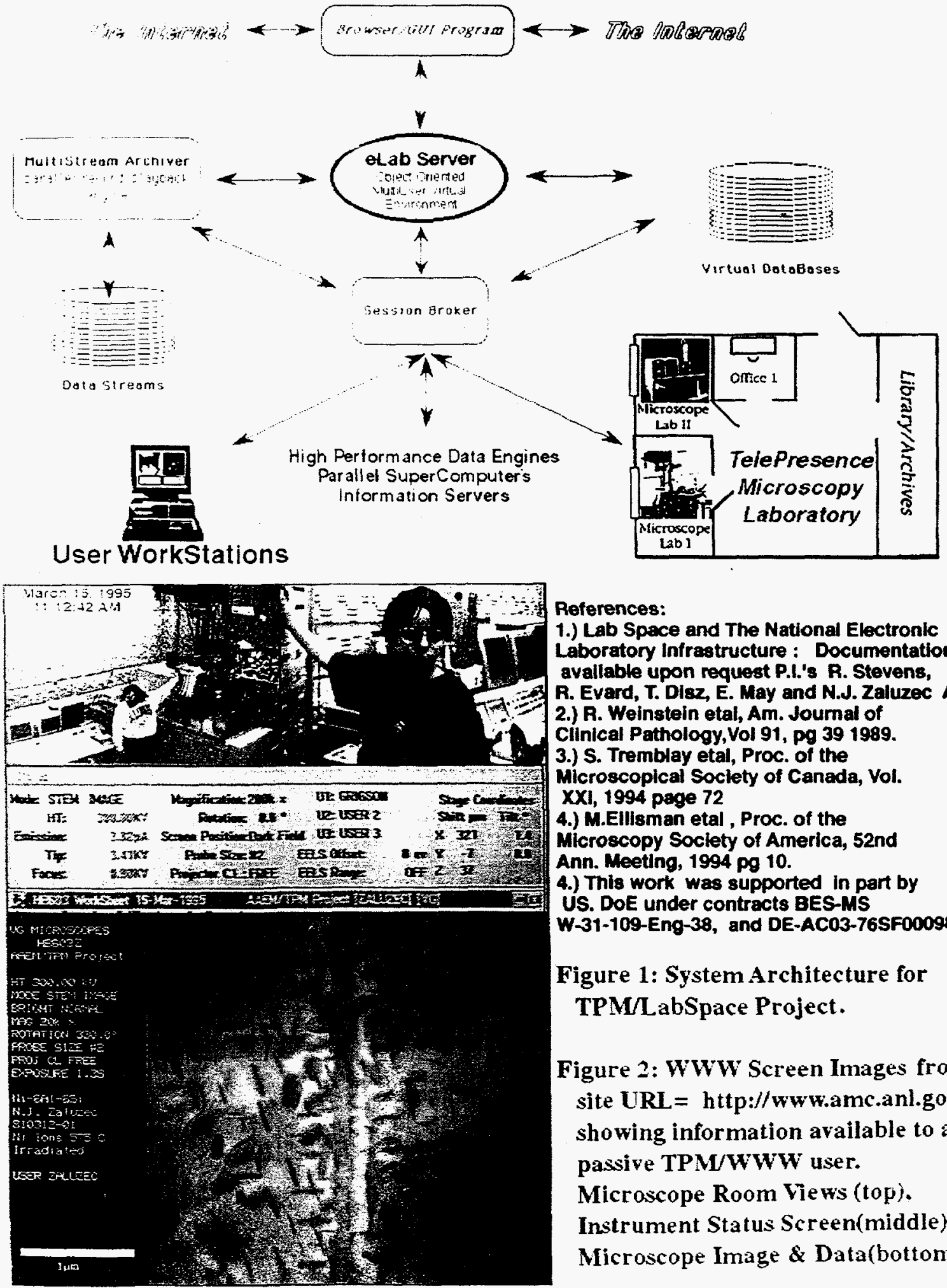

References:

1.) Lab Space and The National Electronic Laboratory Infrastructure : Documentation avallable upon request P.I.'s R. Stevens, R. Evard, T. Disz, E. May and N.J. Zaluzec ANL 2.) R. Weinstein etal, Am. Journal of Cilnical Pathology, Vol 91, pg 391989. 3.) S. Tremblay etal, Proc. of the Microscopical Society of Canada, Yol. XXI, 1994 page 72 4.) M.Ellisman etal , Proc. of the Microscopy Society of America, 52nd Ann. Meeting, 1994 pg 10.

4.) This work was supported in part by US. DoE under contracts BES-MS

W-31-109-Eng-38, and DE-AC03-76SF00098.

Figure 1: System Architecture for TPM/LabSpace Project.

Figure 2: WWW Screen Images from site URL = http://www.amc.anl.gov showing information available to a passive TPM/WWW user. Micrascope Room Views (top). Instrument Status Screen(middle). Microscope Image \& Data(bottom). 